BULLETIN Bulletin hispanique

HispaniquE Université Michel de Montaigne Bordeaux

$120-2 \mid 2018$

Varia

\title{
«El Rey no quiere educación francesa»: Floridablanca contra el Real Seminario de Nobles en los tiempos del pánico
}

"Le Roi ne veut pas d'éducation française". Floridablanca contre le Real Seminario de Nobles aux temps de la "panique"

"The King does not want any French education". Floridablanca against the "Real Seminario de Nobles" in the times of "panic"

\section{María Dolores Gimeno Puyol}

\section{OpenEdition}

\section{Journals}

Edición electrónica

URL: https://journals.openedition.org/bulletinhispanique/6522

DOI: 10.4000/bulletinhispanique.6522

ISSN: 1775-3821

Editor

Presses universitaires de Bordeaux

Edición impresa

Fecha de publicación: 10 diciembre 2018

Paginación: 441-460

ISBN: 979-10-300-0337-6

ISSN: 0007-4640

\section{Referencia electrónica}

María Dolores Gimeno Puyol, ««El Rey no quiere educación francesa»: Floridablanca contra el Real Seminario de Nobles en los tiempos del pánico», Bulletin hispanique [En línea], 120-2 | 2018, Publicado el 02 enero 2022, consultado el 06 enero 2022. URL: http://journals.openedition.org/

bulletinhispanique/6522 ; DOI: https://doi.org/10.4000/bulletinhispanique.6522 


\title{
«El Rey no quiere educación francesa»: Floridablanca contra el Real Seminario de Nobles en los tiempos del pánico
}

\author{
María Dolores Gimeno Puyol \\ Universitat Rovira i Virgili (Tarragona)
}

"Le Roi ne veut pas d'éducation française". Floridablanca contre le Real Seminario de Nobles aux temps de la "panique"

Le Real Seminario de Nobles de Madrid a été placé sous surveillance, en 1791, par le comte de Floridablanca alarmé par ce qu'il nommait le «francesismo» : la pénétration des idées révolutionnaires. Ainsi avait-t-il adopté des mesures contre l'enseignement du français et du Droit Naturel et des Gens. Ses successeurs au Secrétariat d'État, Aranda et Godoy, ont abordé le problème de façon plus pragmatique.

Mots-clés: Real Seminario de Nobles, Floridablanca, enseignement, idées révolutionnaires.

El Real Seminario de Nobles de Madrid sufrió en 1791 la vigilancia del conde de Floridablanca, alarmado por lo que denominó "francesismo", es decir, la penetración de las ideas revolucionarias. Así dispuso medidas contra la enseńanza del Francés y del Derecho Natural y de Gentes. Sus sucesores en la Secretaría de Estado Aranda y Godoy abordaron la situación de modo más pragmático.

Palabras clave: Real Seminario de Nobles, Floridablanca, enseñanza, ideas revolucionarias

"The King does not want any French education". Floridablanca against the "Real Seminario de Nobles" in the times of "panic".

The "Real Seminario de Nobles" in Madrid was subjected to surveillance by the Count of Floridablanca in 1791, alarmed by what he called "francesismo", that is, the penetration of revolutionary ideas. Thus, he set in motion measures against the teaching of French and Natural Law and the Law of Nations. Aranda and Godoy, his successors in the Secretariat of State, solved the situation in a more pragmatic way.

Keywords: Real Seminario de Nobles, Floridablanca, teaching, revolutionary ideas. 
Ta Revolución francesa de 1789 suscitó una lógica alarma en las monarquías europeas. Para prevenir su expansión en la vecina España, el secretario de Estado José Mońino, conde de Floridablanca, adoptó diversas medidas, preso del "pánico", en términos de Richard Herr (197-221). $\mathrm{Su}$ vigilancia afectó a la entrada de textos extranjeros o a los impresos en el interior, y se extendió tanto a quienes hiciesen uso público de la Razón -ilustrados insignes como Cabarrús, Jovellanos o Ramón de Salas- como a los que profiriesen opiniones en ámbitos privados, vigilados por una Comisión Reservada. La sufrieron especialmente los residentes extranjeros, sobre todo franceses, incluidos en un censo al efecto ${ }^{1}$.

Ese clima afectó al Real Seminario de Nobles de Madrid, fundado en 1725 por Felipe V para la educación de "Cavalleros Christianos» (Constituciones 1730: 4). Siendo de patrocinio real, sus Constituciones y funcionamiento dependían del Gobierno, que nombraba a sus directores. Los alumnos cursaban una serie variada de asignaturas: humanísticas, científicas y técnicas, además de formación religiosa y habilidades necesarias en su futura vida social. Se distribuían en diversos niveles o clases, regulados por exámenes; y estaban al cuidado de un director de sala, un eclesiástico que ejercía de tutor de la educación de los asignados a cada una (Aguilar Piñal 330-333, 345).

\section{EL FRANCÉS, LOS FRANCESES Y EL «FRANCESISMO»}

Entre la nobleza española se había extendido la necesidad de dominar el idioma usado por las cancillerías y cortes europeas. Y así, el Real Seminario creado para ella fue la primera institución educativa del país que impartió Francés, materia voluntaria junto al Italiano en las Constituciones de 1725 y enseguida obligatoria en las de 1755. Tan importante se consideraba que una de las salas del Real Seminario era la «francesa», en la que los ayudas de cámara y mozos de retrete eran nativos franceses, "con encargo de que no hablen otra lengua que esta en todas sus funciones» (Plan 10). También lo eran sus profesores: a la sazón, su director el abate Juan de Lapeyre, Dionisio Pelleport, Esteban de Laborda, Juan Selino y Juan Tomás Laures. Varios de ellos residían en el Hospital de los Franceses, dependiente de los reyes de Espańa y Francia ${ }^{2}$.

Para conocer los contenidos y orientación de la asignatura, resultan muy ilustrativos los enunciados de los certámenes públicos ${ }^{3}$. El Francés se evaluaba

1. Sobre las medidas aplicadas a residentes franceses entre 1789 y 1791, ver Elorza (69-117).

2. Fundado en 1615 por el clérigo Henri de Savreux para atender a compatriotas refugiados de guerras o sin recursos, el Hospital era administrado por los franceses más notables afincados en Madrid.

3. El Plan de Estudios vigente, de 1785, establecía su estudio durante un año, con exámenes cada tres meses para verificar el aprovechamiento y promoción a una clase superior y certámenes públicos cada dos años (Plan 15), aunque la práctica fue más irregular. Para mayor detalle sobre la enseñanza del Francés ahí, véanse las entradas «Real Seminario de Nobles», «Laborde» y «Pelleport»-elaboradas por Gimeno Puyol-y «Laurès» - por García Bascuñana- en el DHFE (García Bascuñana 2017). 
mediante ejercicios gramaticales o traducciones de clásicos del siglo XVII como las Aventuras de Telémaco de Fénelon, Oraciones fúnebres de Fléchier y fábulas de La Fontaine, o los más contemporáneos Poema de la Religión de Louis Racine, Conversaciones familiares de Doctrina Christiana entre las gentes del campo, artesanos, criados y pobres de Madame Le Prince de Beaumont y Compendio histórico de la Religión de Joseph Pinton, entre otros. Más que por ser obras de los considerados grandes autores franceses, destacan por su evidente orientación didáctica y religiosa, lo que garantizó entonces su difusión en España, usadas en la educación general en ediciones traducidas o en versión original, aunque el Telémaco fue expurgado por la Inquisición en $1771^{4}$. Varios de esos títulos están también presentes en el primer plan de estudios que trataba el aprendizaje específico de lenguas, redactado por González Cañaveras en 1767 para el Seminario y Real Academia de Lenguas y Ciencias de Cádiz: los de La Fontaine y Fénelon en la clase de Rudimentos y a Fléchier y Racine, sin especificar, en la de Sintaxis 5 .

En cuanto a los profesores que los impartían, algunos de ellos eran clérigos, llevaban años asentados en España y se habían hecho acreedores de estima y respeto. No obstante, se cernió sobre ellos la acción de Floridablanca, alarmado con la deriva revolucionaria, que en 1790 había dictado la Constitución Civil del Clero.

Quien primero la sufrió fue el catedrático Esteban de Laborda -Bordes, La Borda o De Bordes, según firma-, por un oscuro incidente sucedido fuera de la institución. Una delación -luego cuestionada- lo señalaba el 22 de febrero de 1791 charlando con otros franceses en la céntrica calle madrileńa de la Montera, frente al negocio de Geniani, cuando se sumó a uno de ellos que atacaba al Gobierno y justicia espańoles por impedirle el subarriendo de una tienda, "ofreciendo al que se quejava empeños que el podría proporcionar, y pasó á traer a la conversacion las personas mas elevadas de ambos sexos» ${ }^{6}$. Enseguida, el 26 de febrero, el fiscal del Consejo de Castilla Campomanes cursó una orden a Gonzalo José de Vilches, alcalde de Corte, para que apercibiese al maestro. Otra orden del 21 de marzo, más conminatoria, parece revelar que no se corrigió: «se save que sigue hablando con poco respeto del Gobierno. En su conseqüencia encargo á VM vuelva á adbertir á Mr. La Borda se abstenga de repetir sus conversaciones por que de continuarlas no podra permanecer

4. Lépinette $(54-65,78)$ destaca la presencia de ese tipo de obras en la enseñanza del francés en España, como también la difusión general de literatura religiosa, textos didácticos, técnicos y científicos franceses, incentivados por el desarrollo editorial pero con la vigilancia de la Inquisición.

5. El Plan de Educación de González Cañaveras -editado en 1767, 1782 y 1794- incluía además: el Catecismo y las Costumbres de los Israelitas y Cristianos de Fleury, la Historia de la Biblia de Royaumont, el Discurso sobre la Historia Universal de Bossuet y los autores Marsolier, Fontenelle y Despréaux, junto a clásicos latinos (cit. por Fernández Fraile 93).

6. AHN, Universidades, leg. 689, informe de Vilches a Aranda, 6 junio 1792. Contiene una «Nota» del conde de Campomanes sobre el suceso denunciado del 3 de marzo de 1791. Y citas siguientes. 
en Madrid, añadiendole VM evite concurrencias que le puedan perjudicar». Tras otra advertencia, Laborda protestó por lo infundado del cargo, pero acabó desterrado un mes después por una orden del 21 de abril del conde de Cifuentes, Presidente del Consejo de Castilla. Obligado a separarse treinta leguas de Madrid y Reales Sitios, salió el día 26 siguiente, instalándose al final en Valladolid, a cuyas autoridades judiciales se avisó «à fin de que observaran su conducta, y dieran cuenta à S. E. de cualquiera cosa que notáran en ella».

Durante el verano de 1791 Floridablanca no bajó la guardia. En Francia había fracasado la fuga de la familia real en Varennes, y el 14 de septiembre Luis XVI juraría la Constitución ante la Asamblea. Esta vez cayó en su punto de mira todo el Real Seminario. Tal vez por la delación de su capellán mayor, Francesco Scuditti, o por otras informaciones, el ministro llamó al prelado para encargarle tareas de espía: "Quando ebbi il piacere di parlare a V. E. nella Segretaria, le sue ultime parole furono che le scrivessi tutto ciò che potessi occorrere», escribe este en italiano -lengua en que debieron de charlar- para describir una situación alarmante, de consecuencias imprevisibles: "Punti di religione e d'indipendenza sono gli oggetti ambidue troppo scandalosi per un luogo come questo. La libertà con cui certi soggetti insegnano ed educano ha portato a me stesso varie querele di Genitori e d'alcuni Direttori di questi Alumni» ${ }^{7}$. Es la ideología ultramontana, que profesaban tantos clérigos, dispuestos a censurar a los portavoces de las peligrosas Luces francesas (Elorza 75).

Ya con la fuerza de las sospechas fundadas, el secretario de Estado escribió el 4 de noviembre una carta "privada» al director del Real Seminario, Antonio de Angosto ${ }^{8}$, comunicándole que sabía que en sus salas se hablaba y enseñaba "con libertad máximas peligrosas a la Religión y al Estado, en puntos de independencia, que son los que han perdido a nuestros vecinos los franceses»? El peligro, arraigado en la institución formativa de los futuros dirigentes, determinaba una drástica medida: «El Rey no quiere educacion francesa, y asi con qualquier pretexto es menester desacerse de Maestros, y Directores franceses, ó se les jubilará ó privará de serlo».

Un segundo objetivo eran Manuel de Condado, catedrático de Derecho Natural y de Gentes, y sus mejores alumnos:

También se recela de Condado, y sus Alumnos mas adelantados, y esto es mui serio, y traerá malas consecuencias para V. S. y para todos. El estudio del Dcho. natural, y de gentes, y el publico de las Naciones, como el de la Fisica y Metafisica pide mucho juicio, para no deslizarse como hacen los extrangeros, y venir a parar en Deistas, Materialistas, ó independientes, queriendo hacer á la razon humana juez de todo, sin respeto á la revelacion y á las Stas. Escrituras. Digo a V. S. que la cosa no admite paliativos, sino quiere perderse, $y$ perder esa Casa; $y$ asi por Dios propongame

7. AHN, Estado, leg. 2863, exp. 11, doc. 1, Scuditti a Floridablanca, 1 septiembre 1791.

8. Antonio de Angosto y Rodríguez, brigadier de Artillería, fue nombrado director del Real Seminario de Nobles el 14 de septiembre de 1783 (Peset 1981: 527-533).

9. AHN, Estado, leg. 2863, exp. 11, doc. 2, Floridablanca a Angosto, 4 noviembre 1791. Y cita siguiente. 
lo que le parezca en carta reservada para salir de toda Persona sospechosa en puntos de francesismo, religión y política, en inteligcia. que en caso de qualquier demora podrá ir de por acá un golpe, que meta ruido ${ }^{10}$.

En la lógica del ministro -vecina a los postulados inquisitoriales-, los contenidos de la asignatura propiciaban cuestionar el absolutismo monárquico y la religión católica. Lo etiquetaba con un neologismo: el "francesismo", es decir, las ideas revolucionarias, que podían profesar nativos franceses o los partidarios de la nueva filosofía, también francesa.

Angosto contestó tres días después. Muy cauteloso, retomaba los términos de su remitente relativos a la «falta de Religión y a los puntos de independencia que son los que han perdido á nros. vecinos» ${ }^{11}$. Y esbozaba el retrato de una institución controlada y adecuada a la ortodoxia político-religiosa, en hábil defensa de su papel como director. De sus directores de sala afirmaba que eran «escrupulosos y timoratos y me avisan cuando oyen alguna palabra disonante [...] pues saven mui vien que el mas minimo asomo de falta de Religion debe mirarse con la máxima atencion porque en esto estriva nra. felicidad, tanto para nuestra Alma como para el bien del Estado»; además, se reunía con ellos cada sábado para tratar de las cosas «espirituales» del Colegio, de lo que podían dar fe el capellán mayor Scuditti y el P. Portillo. Obediente con la orden relativa a los maestros franceses, incluso minimizaba las consecuencias personales de su despido, pues se podían mantener con las clases que impartían fuera del Seminario. Por ello, si hallaba motivo, aunque «leve», los despediría. Pero intercedía por Dionisio Pelleport porque hacía trece años que enseñaba ahí "con particular aplicación", solicitando se mantuviese su comisión en el Hospital Francés, donde confesaba y hacía otros oficios; y pedía para todos algún auxilio.

Además de la carta del ministro, Angosto recibió el 20 de noviembre una delación directa del celoso Scuditti sobre la última reunión de directores de sala del Real Seminario, celebrada el 31 de octubre, en cuyo transcurso el abate francés Juan de Lapeyre había proferido peligrosas opiniones sobre el gobierno de Francia y circunstancias de su Rey ${ }^{12}$. Sensible a la vigilancia externa e interna, se apresuró a recabar sendos informes de los asistentes y comunicarlos a Mońino; a ellos se remitía, ya que, primero por una indisposición y luego porque salió a peinarse, su presencia fue intermitente, y concluía adulador -con ortografía seseante- que esos asuntos «merecen el pulso e integridad de V.E. que tanto conose a los hombres y sabe sus pasiones mejor que nadie» ${ }^{13}$.

10. Ibid. El término francesismo -que destaco- lo usa Floridablanca y luego Angosto en su respuesta; medio siglo después, Salvá (1846) lo documenta por primera vez en su diccionario como sinónimo de 'galicismo'.

11. AHN, Estado, leg. 2863, exp. 11, doc. 3, Angosto a Floridablanca, 7 noviembre 1791. $\mathrm{Y}$ citas siguientes.

12. Ocho eclesiásticos eran directores de sala: Josef Pérez y Joven, Lorenzo Martínez, Rafael Pérez, Josef Manuel de Trigo, Juan Bautista Lapeyre, Joseph Sánchez Ortiz, Pedro Pasqual de Luxán y Juan Bautista Alzamora, pero no todos asistieron a esa reunión.

13. AHN, Estado, leg. 2863, exp. 11, doc. 4, Angosto a Floridablanca, 21 de noviembre. 
Aunque Angosto precisaba «que todos los Directores de Sala son opuestos al Director Francés», solo dos de los cuatro informes emitidos manifiestan posiciones claramente ultramontanas e inculpatorias contra Lapeyre, entre ellos el del capellán Scuditti, que resumía así sus palabras:

que el gobierno de Francia jamás se ha hallado en estado mejor que al presente: que es fuerte cosa que tantos miliones de gentes dependiesen del capricho de un hombre solo, y más del nuestro (dando a entender el Rey de Francia) que..., acompañó esta palabra con el ademán de levantar la mano a la boca como en acto de quien bebe; y añadió que en menos de diez ańos los Franceses se sorbirían toda la Europa o todo el mundo. Después se habló de la abundante cosecha de aquel Reyno, y de lo floreciente que está en el día, atendida la nueva constitución; y por último quiso dar a entender (según me hizo advertir después cierto sujeto) que dentro de poco tiempo todas las naciones le debían imitar ${ }^{14}$.

El informe de José Pérez, director de la Sala $4^{\mathrm{a}}$ y también presbítero, coincidente con el anterior, transcribía tres proposiciones o frases literales del sospechoso: "1 $1^{\text {a }}$ Nunca ha estado la Francia mejor que ahora. 2a Antes de 10 años se absorberá el mundo. $3^{\mathrm{a}}$ No es razón sujetarse a un hombre y especialmente a uno que bebe mucho según dio a entender con el ademán de llevarse la mano a la boca»" ${ }^{15}$. Afirmaba actuar en "cumplimiento de mi obligación y en obsequio a la verdad», porque dichas declaraciones "no me parecieron conformes a la doctrina de Jesuchristo, que nos manda obedecer y respetar a los Reyes», según ya había comentado con Scuditti.

En cambio, Pedro Luján minimizó cualquier alarma en su respuesta, libre de preámbulos morales, limitándose a transcribir lo que recordaba de la intervención del abate:

que era falso lo que algunos suponían de haber sido año escaso de frutos en la Francia, por falta de Cultivo, que todo esta más abundante y varato que antes, que el Rey se allava también mejor, porque sin cargo ni cuidados podía gastar y comerse lo que le havían consignado, donde y como le acomodase; y del sistema de la Francia y gobierno que observaba, en breves años algunas potencias le havían de seguir o imitar por conocer las ventajas ${ }^{16}$.

Es más, circunscribía los hechos al terreno de la economía, un problema para la endeudada monarquía de Luis XVI, de cuyo giro constitucional realizaba una velada alabanza. Frente a las leyes de Jesucristo, él invocaba las de su conciencia: «es lo que puedo hacer recuerdo, y decir a V. S. vaxo de mi conciencia».

Ni en contra ni a favor es la declaración de José Manuel de Trigo, director de Sala 2a hábilmente neutral. Suministra primero detalles circunstanciales sobre

14. AHN, Estado, leg. 2863, exp. 11, doc. 5, Angosto a Scuditti y respuesta de este, 20 noviembre 1791.

15. AHN, Estado, leg. 2863, exp. 11, doc. 6, Angosto a Pérez y respuesta de este, 20 noviembre 1791.

16. AHN, Estado, leg. 2863, exp. 11, doc. 7, Angosto a Luján y respuesta de este, 20 noviembre 1791. 
Lapeyre -en qué silla estaba sentado- y que replicó «Que en Francia podían ir a tratar esos puntos de derecho porque hallí sí que lo entendían. Que los franceses dentro de diez ańos se sorverían al mundo.» ${ }^{17}$. Lo siguiente lo refiere a partir de lo que le contaron, en concreto la crítica al monarca absoluto según las versiones de Scuditti y Pérez, ya que hubo de ausentarse por un asunto grave de su clase, y no concluye con apelación alguna.

$\mathrm{Al}$ acusado Lapeyre no se le requirió su propia versión -o no consta en el expediente-. Según su colega Francisco Javier Wadingo, presbítero y catedrático de Filosofía Moral, era conocido en el Real Seminario como «el abate Crillon», un apelativo cargado de ironía ${ }^{18}$. Curiosamente, las acusaciones reseñadas no produjeron consecuencias inmediatas en él. Y es que, al parecer, gozaba de la protección del director Angosto, denunciada tiempo después, durante la visita decretada por Manuel Godoy a principios de 1793, entre otros por el citado José Pérez y por Juan Bautista de Alzamora, director de la Sala $7^{\mathrm{a}}$, pues "profería proposiciones poco religiosas y de algún escándalo para sus alumnos», de lo que dimanó un desorden evidente en la Sala $5^{\mathrm{a}}$, que dirigía ${ }^{19}$.

Quien resultó despedido, aplicando al pie de la letra lo de «qualquier pretexto» que apuntó Floridablanca, fue Juan Tomás Laures -Laurel o Laurès-, el tercero de los maestros franceses, al que Angosto había hallado culpable «de cierta disputa que tubo con el segundo», es decir, Juan Selino -Serinó o De Selino $-{ }^{20}$. En su orden a la Contaduría del Seminario para que ajustase su cuenta, tras repartir sus alumnos entre los otros maestros, argumentaba que «anda escribiendo a uno y a otros, exasperando los ánimos, contra la quietud que debe haber en este establecimiento", un mal ejemplo para los caballeros seminarista ${ }^{21}$. No era exactamente un caso del «francesismo» que se pretendía conjurar.

Laures, haciendo honor a su reputación de indiscreto, enseguida comenzó a difamar por los mentideros de la Corte a quienes consideraba causantes de su despido: el investigado abate Lapeyre y su rival el capitán y catedrático Selino. Este, que conoció los chismes por dos compatriotas suyos -un tal Lelon, ayuda de cámara del conde de Jaruco, y Argenson, jefe de cocina del duque de Granada-, se quejó por escrito al director Angosto. La Superintendencia de Policía tomó entonces declaración a los testigos. Según Lelon, Laures presumía de haber propiciado el despido «al instante y sin réplica» de sus dos colegas citados tras entrevistarse con el mismo Floridablanca; mientras Argenson mencionaba su temor a ser echado de Madrid por una carta «insolente y mui

17. AHN, Estado, leg. 2863, exp. 11, doc. 8, Angosto a Trigo y respuesta de este, 20 noviembre 1791.

18. El abate Crillon, Louis Athanase des Balbes de Berton (1726-1789), era autor, entre otras obras, de las Mémoires philosophiques du baron de ${ }^{* * *}$ (Vienne en Autriche, s. n., 1777), en que desacreditaba a los philosophes bajo una trama de ficción.

19. AHN, Universidades, leg. 690/2, exp. 5, f. 10r, 6 febrero 1793.

20. AHN, Estado, leg. 2863, exp. 11, doc. 10, oficio de Angosto a Floridablanca, 15 diciembre 1791.

21. AHN, Estado, leg. 2863, exp. 11, doc. 11, Angosto a la Contaduría, 14 diciembre 1791. 
clara» que dirigió a Selino y su conversación con él a las 9 de la mañana del 13 o 14 de enero en la calle de Jacometrezzo -la del Hospital Francés- cuando iba a dar clases particulares, desdeńando una oferta del ministro de reingresar en el Real Seminario ${ }^{22}$. La queja fue zanjada con una simple advertencia al difamador ${ }^{23}$.

Las palabras atribuidas a Laures parecen pura jactancia, pues unos días antes, el 7 de enero, se había decretado el cierre de la sala francesa en los siguientes términos:

El Rey ha reparado q en la relación de salas de ese seminario aya una con el título de francesa $q^{e}$ parece ser la $5^{a}$ no siendo necesaria ni conducente en las circunstancias actuales. En consequenc a de esto ha resuelto SM qe cese dha Sala; que sus Alumnos se distribuyan entre las demas, y qe cese su Director y se retire del Semin ${ }^{\text {rio }}$ reteniendo el suelo $\mathrm{p}^{\mathrm{r}}$ tiempo de un año, para que en él pueda elegir dho destino fuera de $\mathrm{Mad}^{\mathrm{d}}$ y Sitios $R^{s}$. Con este motivo deberá subsistir por ahora solam ${ }^{\text {te }}$ el primer Maestro de lengua francesa, despidiéndose a los demás como inútiles en el dia ${ }^{24}$.

El 13 de enero Angosto remitía a Floridablanca el cumplimiento de la orden: «todos han abrasado [sic] con mucha resignación las $\mathrm{R}^{s}$ disposiciones, y queda todo executado como V. E. me lo previno»" ${ }^{25}$. Quedaba solamente su recomendado el clérigo Pelleport, primer maestro de lengua francesa.

La tajante orden ministerial se sumaba al destierro de Laborda por unas declaraciones en la vía pública, a la denuncia a Lapeyre por sus compañeros espías y al expediente de Laures por unos chismes. La comunidad francesa, muy relacionada entre sí y bien integrada en la vida e instituciones madrileñas, había quedado bajo sospecha en aquel ambiente temeroso de la Revolución.

\section{FiLOSOFÍ́A Y NUEVAS IDEAS}

A diferencia del Francés, asignatura instrumental que se practicaba con textos de moralistas franceses o literatura educativa, el área de la Filosofía albergaba en sí el germen de la crítica. Concretada en el Derecho Natural y de Gentes, el Derecho Público de las Naciones e incluso la Física y la Metafísica, para Floridablanca -en su citada carta del 4 de noviembre de 1791-amenazaba con entronizar la razón humana cuestionando la religión católica y el Estado absoluto.

Las Constituciones fundacionales del Real Seminario consideraban la Lógica, la Filosofía, la Metafísica y el Derecho Canónico facultades mayores, reservadas a los alumnos más capacitados, complementarias de las lenguas

22. AHN, Estado, leg. 2863, exp. 11, doc. 23, informe de Gervasio Fernández Izquierdo al Superintendente de Policía Mariano Colón, 20 enero 1792: contiene copia el oficio de Angosto a este (16 enero 1792) y la minuta de las declaraciones de los sirvientes franceses.

23. AHN, Estado, leg. 2863, exp. 11, doc. 22, Colón a Floridablanca, 20 enero 1792.

24. AHN, Estado, leg. 2863, exp. 11, doc. 30, 7 enero 1792, Floridablanca a Angosto.

25. AHN, Estado, leg. 2863, exp. 11, doc. 20, 13 enero 1792, Angosto a Floridablanca. 
(Constituciones 1730: 6-7) ${ }^{26}$. El Plan de Estudios de 1785 establecía una clase de Lógica y Metafísica, cuyo estudio duraba un año, repitiéndolo si era necesario, en que se explicaban la Dialéctica y partes de la Metafísica -Psicología, Ontología y Teología Natural-; y otra clase de Filosofía Moral, Derecho Natural y de Gentes, cuyo estudio duraba dos años a razón de dos horas cada mañana (Plan 4-5). Sin embargo, existían separadas la cátedra de Filosofía Moral, que ocupaba el presbítero Francisco Javier Wadingo desde 1786, y la de Derecho Natural y de Gentes, ostentada por el mencionado Manuel Joaquín de Condado desde 1783. Andrés de Dios Cobo era el catedrático de Lógica y Metafísica desde $1784^{27}$.

El Derecho Natural se había establecido como asignatura en Heidelberg en 1661, con Pufendorf titular de la cátedra, y difundido desde entonces en otras universidades europeas; sus contenidos eran heterogéneos, orientado tanto al derecho de gentes como a la forma correcta de establecer el derecho o a la práctica del buen gobierno, cobrando importancia como justificación del sistema jurídico de la Europa Moderna y del poder del soberano ${ }^{28}$. De ahí que interesase en la reforma universitaria de Carlos III, propuesto por Mayans y por Olavide en sus respectivos Planes de Estudios de 1767 y 1768, y finalmente implantado en los nuevos Reales Estudios de San Isidro, que convocaron la cátedra correspondiente en 1771 (Mariano y José Luis Peset 1975: 144-146; Jara Andreu 41-49) ${ }^{29}$. Sin embargo, el yusnaturalismo racionalista moderno había sido formulado por protestantes como Heinecio, Grocio, Burlamaqui y el citado Pufendorf, que practicaron un ataque sistemático al yusnaturalismo escolástico anterior; así Mayans proponía versiones expurgadas de sus obras para uso de los alumnos, mientras que los primeros opositores destacaban sus «errores» y recurrían a las Sagradas Escrituras como argumento de autoridad ${ }^{30}$.

Estos datos revelan la progresiva diferenciación del ámbito de la Filosofía, que fue ampliando contenidos, según se ve en los certámenes de los sucesivos ejercicios literarios desde diciembre de 1788, que ya examinaban el Derecho Natural. Condado, que quedó segundo en las siguientes oposiciones a la cátedra de Derecho Natural y de Gentes de los Reales Estudios en 1782, tras José Ferrer y Bardají, había pasado entonces a ejercer la homónima del Real Seminario de Nobles, donde no se precisaba oposición (Viñao Frago 1194-

26. A las citadas asignaturas se añadieron luego la Filosofía Moral y la Física General, Particular y Experimental (Constituciones 1755: 203).

27. Wadingo y Cobo indican su fecha de ingreso en el Seminario en sus respectivas declaraciones al visitador inquisitorial en 1793 (AHN, Universidades, leg. 690/2, exp. 5). De Condado aporta datos Viñao Frago (1195): ver nota 62.

28. Para los orígenes del yusnaturalismo racionalista, ver Rus Rufino (48-49, 50-57, 97-98).

29. El Derecho Natural se implantó luego en la universidades de Granada, Valencia, Valladolid y Santiago (Rus Rufino 142).

30. Grocio, Pufendorf, Burlamaqui y Heinecio fueron conocidos en España a pesar de no estar permitidos por la Inquisición (Mariano y José Luis Peset 1975: 144). Sobre su tratamiento en las disertaciones de los opositores a los Reales Estudios, entre las cuales la del ganador Joaquín Marín, ver Rus Rufino (82-98, 105-127). 
1198, 1204; Rus Rufino 134). Allí, aunque atento a los límites de la monarquía absoluta, incluyó novedades ilustradas, como revelan los ejercicios literarios que preparó para el certamen citado: elementos racionalistas como la igualdad natural de derechos y obligaciones y la exención de prerrogativas en ese estado, y elementos sensualistas que abogaban por el placer y el rechazo del dolor; incluso desarrollaba la Ciencia Política con las ideas de Rousseau, Montesquieu y Locke en torno al contrato social, la separación de poderes y el control de la soberanía, u otros de política práctica que presagian el liberalismo y apuntan a la nueva disciplina de la Economía Civil ${ }^{31}$.

Se entiende fácilmente que la asignatura estuviese en el punto de mira de las autoridades tras la Revolución francesa. En su novedad, heterogeneidad y carácter práctico, era la puerta a las nuevas teorías y escritos de los filósofos extranjeros, abierta en la institución educativa de los jóvenes nobles. Como se ha dicho, Floridablanca inquirió sobre ella al director del Real Seminario al advertir ahí los peligros del «francesismo»; la respuesta de este manifestaba incertidumbre, teñida de temor: "Yo no se que decir a V. E. de esta enseñanza y de la Fisica y Metafisica, porque como estos estudios son para iluminarlos y discurrir más y más en todos los asuntos, suelen algunos deslisarse á lo malo y separarse de lo bueno, y caen luego en lo que $V$. E. con tanta reflexion discurre» $^{32}$. Afirmaba haber prevenido hacía tiempo a Condado sobre sus enseñanzas de libertad e independencia, que habían despertado rumores y críticas; pero minimizaba su acción porque hacía cuatro meses había dejado de asistir al centro sin razón explícita y para entonces tenía un suplente.

Esto sucedía en noviembre de 1791. El 21 de diciembre, un mes después de la denuncia del capellán Scuditti al director francés Lapeyre, el catedrático de Filosofía Moral Wadingo realizaba otra al caballero Terry, alumno suyo: había advertido en él menosprecio o escepticismo hacia las verdades sagradas impartidas en sus clases y alguna palabra suelta sobre «los derechos de la soberanía, libertad absoluta de los hombres, y otros puntos relativos al sistema diabolico» que amenazaba con introducirse en España, es decir, la ideología revolucionaria francesa ${ }^{33}$. Otros directores de sala podían corroborar sus sospechas en cuanto a la religión, y él mismo concretaba que hacía cuatro días, antes de la clase, le expresó «con bastante satisfaccion que ya Inglaterra se habia sacudido del yugo de la soberania siguiendo el sistema y nueva constitucion de la Francia», que el tiempo demostraría ser "mas justa y ventajosa [...] para un estado». Wadingo, que decía ajustar sus enseñanzas a «la divina Revelación para rectificar con esta luz la de nuestra propia razón, obscurecida y ofuscada», también señalaba a los caballeros Pardo y Navia, «tocados de los mismos principios y perniciosas máximas», aunque, menos atrevidos y talentosos, no

31. Viñao Frago (1199-1202) ha realizado un detallado análisis del Certamen de diciembre de 1788 y del papel de Condado en la consolidación de la Ciencia Política. Sobre los contenidos asociados a la Economía Civil, ver Cervera Ferri (en línea).

32. AHN, Estado, leg. 2863, exp. 11, doc. 3, 7 noviembre 1791, Angosto a Floridablanca.

33. AHN, Estado, leg. 2863, exp. 11, doc. 12, Wadingo a Angosto. Y citas siguientes. 
se expresaban como Terry. Afirmaba actuar como ministro de la Religión y servidor del Rey, preocupado porque entre sus alumnos del Real Seminario se habían introducido «sobre Religión y Soberanía las más perniciosas y detestables máximas», de lo que derivarían consecuencias «mui funestas a nuestra España». Otro clérigo ultramontano.

Ante estas acusaciones, el 7 de enero de 1792, día en que decretó el cierre de la sala francesa, Floridablanca envió al director Angosto sendas órdenes de encerrar al caballero díscolo y de practicarle un interrogatorio y un careo con su denunciante ${ }^{34}$. José Terry -a quien su maestro Pelleport incluía entre la lista de los "Aplicados»" ${ }^{35}$ - negó los cargos, como también que fuese alumno de Derecho Natural. No cabe, pues, ver en él una inoculación directa de las enseñanzas de Condado, sino tal vez de la Lógica y Metafísica que decía cursar -e impartía Cobo-. De hecho, Wadingo, un año después, durante la mencionada visita inquisitorial, achacaba a las «ideas perniciosas sobre varios puntos de la Philosofia práctica» los desórdenes anteriores entre los seminaristas, que procedían del aula de Lógica y Metafísica, «en la qual se estudian estas dos partes de la Philosophia especulativa por el Ernesto Autor nada conveniente para la enseñanza [...] por su sistema philosophico» ${ }^{36}$; aunque no lo indicase, este filósofo y teólogo luterano había sido editado por $\mathrm{Condado}^{37}$. Además, notaba con alarma la nula inclinación de los alumnos al estudio de la Divina Revelación, que él reputaba necesaria para rectificar la razón humana, junto a otros errores "propios del sistema philosophico del dia».

A pesar del cierre de fronteras y de la vigilancia gubernamental o inquisitorial, el escepticismo religioso y las ideas constitucionales se habían difundido en España. En Madrid circularon copias de la Constitución francesa de septiembre de 1791, que establecía una monarquía parlamentaria con un poder ejecutivo débil ${ }^{38}$.

\section{A modo de desenlace: entre Aranda y Godoy}

Mientras Floridablanca trataba de conjurar la penetración del «francesismo», en Francia seguía muy amenazado el trono de Luis XVI. En ese contexto difícil, en febrero de 1792, Carlos IV lo apartó de la Secretaría de Estado, sustituyéndolo

34. AHN, Estado, leg. 2863/1, docs. 28, 29, 7 enero 1792: órdenes de Floridablanca; doc. s/n, 10 enero: borrador del interrogatorio a Terry; y doc. 31, 13 enero: borrador de Angosto al ministro sobre las diligencias practicadas. El careo se suspendió a petición de Wadingo.

35. AHN, Universidades, leg. 689/2, exp. 5, «Relación de los Caballeros Seminaristas qe se hallan en la Aula de Propiedad de Lengua francesa de mi cargo...", 31 octubre 1788, Dionisio de Pelleport. José Terry figura en el grupo destacado en varias relaciones de su aula.

36. AHN, Universidades, leg. 690/2, exp. 5, f. 12v-13r, 7 febrero 1793.

37. Ioannis Aug. Ernesti, Metaphysica et Logica, cum praefatione, disputatione prooemiali et notis Emmanuelis Ioachimi de Condado, Matriti, In Typograhia Regia, 1785. Ver Álvarez de Morales (275).

38. La Embajada francesa en Madrid informó de la circulación de trescientas copias manuscritas de la nueva Constitución (Herr 209). 
por el conde de Aranda, Grande de España, militar y pragmático, a quien tocó resolver los expedientes incoados en el Real Seminario de Nobles ${ }^{39}$.

El de Esteban de Laborda se reabrió un año después por una petición del interesado de que se le levantase el destierro, «mayormente cuando el suplicante ignora qualesquiera delito que se le haya querido imputar ageno a su notoria honradez, lealtad y carácter ${ }^{40}$. Esgrimía en su abono los servicios prestados durante 15 años -aludía al aplauso a sus exámenes públicos- y recordaba los 21 hijos que tenía, entre ellos un subteniente del Regimiento de Infantería de Granada, servidor del Rey. Su situación se agravaba en Valladolid, «Pueblo por su naturaleza escaso de personas inclinadas al conocimiento de las lenguas y mucho menos de la francesa, [donde] apenas encuentra con quien poder ejercer su ministerio», y porque además carecía del sueldo anterior, cuyo restablecimiento había solicitado en vano su mujer, Lucía Martín, enferma por el clima del lugar.

Aranda se dirigió primero al director Angosto, quien dijo conocer solamente el comunicado que le había enviado en su momento -27 de abril de 1791- el alcalde de Corte Gonzalo José de Vilches - quien había ejecutado las órdenes de apercibimiento y destierro de Laborda-; no en vano los hechos habían sucedido fuera del Real Seminario ${ }^{41}$. Como las pesquisas de Vilches dedujeron que todo se debía a la calumnia de dos particulares, se reabrieron las investigaciones, interrogando a ambos ${ }^{42}$. El primero, Juan Antonio Relaño, contestó vaguedades sobre los partes cursados contra Laborda -a quien aseguraba no conocer-, de los que no recordaba el número ni el comisionado que los dio ni las disposiciones adoptadas contra él. El segundo, Luis Abad de Burgos, declaró que todo era una venganza del anterior, cabo del Juzgado de Policía, porque Laborda «improporcionava algunas providencias» ahí contra él, valiéndose de su buena relación con el superintendente de Policía Mariano Colón y con su hermano José, de quienes había sido maestro de lengua francesa; e incluso afirmó que las órdenes se cursaron a partir de las acusaciones escritas del delator al anterior ministro de Hacienda, el ya difunto Pedro López de Lerena, sin los testigos ni las firmas pertinentes. Concluía Vilches que, sin tener a la vista los partes originales de la comisión, no se podía descubrir claramente a su autor y cómplices, aunque se inclinaba a creer que los cargos contra Laborda eran infundados y excesivas las consecuencias. No resultaba difícil en aquel ambiente enrarecido de 1791 inventar injurias políticas y acabar así con la carrera de un enemigo o rival.

39. Aranda, advirtiendo los peligros de una guerra con las autoridades revolucionarias, abogó por la neutralidad (Albiac 147-150).

40. AHN, Universidades, leg. 689, petición de Esteban de Laborda sin destinatario expreso [«V. M.»], 6 mayo 1792 (y la cita que sigue). Al margen va anotada la orden: «Informe el Director del Seminario y si sabe o presume la causa del procedimiento».

41. AHN, Universidades, leg. 689, Angosto a Aranda, 10 mayo 1792.

42. AHN, Universidades, leg. 689, informe de Vilches a Aranda, 6 junio 1792; resume toda la documentación y órdenes generadas desde abril de 1791. 
En cuanto al caballero seminarista José Terry, el ministro Aranda conoció por casualidad su situación, habiendo sido remitido su expediente a Floridablanca el 28 de febrero de 1792, el día en que era cesado en el cargo, sin que Angosto se lo indicase: «de manera que por la voz publica, y aver tenido la ocasion de saber de un fragmento de las primeras ordenes; tuve que acudir a V. S. para preparar la expedicion ${ }^{43}$. Le urgió entonces a enviarle todos los papeles relativos a Terry y al cierre de la quinta sala, pero faltaba la carta de denuncia de Wadingo, que el director dijo haber entregado a su predecesor, quien -según se excusóle "mando de palabra suspendiese las demas diligencias» ${ }^{44}$. Esta irregularidad incrementó aun más el enfado del nuevo secretario de Estado, quien no lograba encontrar los papeles de la causa en la Secretaría ${ }^{45}$. Debió de ponerla patas arriba, y tres días después apareció el expediente, interpolado entre otros en una arquita que había sobre la mesa del despacho. Pudo así proceder, y como en el anterior caso se remontó al inicio: a las denuncias de los eclesiásticos Scuditti -la cual motivó la disolución de la sala francesa- y Wadingo, de cuya «especie de difusa y vaga delacion señalando particularmente al Cavallero Terry» derivó un encierro incomunicado desde el 7 de enero, que aún seguía "con la misma estrechez» ${ }^{46}$. Aranda consideró, en fin, desproporcionado aquel encarcelamiento: «La publicidad de este suceso ni por la causa atribuida, que indica un descuido en la Direccion; ni por el rigor del procedimiento con un joven de 17 años, no ha merecido la publica aceptacion", por lo que decretó su liberación, aunque también que se le advirtiese de evitar discursos inconvenientes. Su informe, que redactó él mismo, reconvenía con severidad a Angosto por su mala gestión preventiva de los comentarios sobre religión y política en la institución, "pues aplicando V. S. la vigilancia de un Director con leves correcciones podia haverlos precabido; tanto mas facilmente que las edades y la cuna de estos alumnos son susceptibles de las impresiones mas puras», y porque tampoco a posteriori supo gestionar una "causa que se reducia a indiscreciones de un menor edad, punibles por terminos persuasivos, y otras mortificaciones adaptables a ella». Angosto alegó en su descargo que informaba a diario y en persona a Floridablanca «de quanto pasaba en el Seminario y resolvia verbalmente en todos los puntos que merecian su superior decision $»^{47}$. Es evidente la diferencia de métodos entre ambos secretarios de Estado.

José Terry salió, pues, de su encierro. Sus problemas fueron entonces económicos: había fallecido su padre, Jeremías, militar de profesión, y su madre solicitó permiso y subvención real para que él y su hermano Juan, también caballero seminarista, ingresasen en un seminario católico de Londres

43. AHN, Estado, leg. 2863/1, doc. 25, Aranda a Angosto, 25 marzo 1792, informe de la causa contra Terry y su resolución: tres copias, una de ellas el borrador autógrafo de Aranda.

44. AHN, Estado, leg. 2863/1, doc. 26, Aranda a Angosto, 16 marzo 1792; doc. 27, Angosto a Aranda, 17 marzo 1792: dice enviar sus borradores autógrafos para proceder con más celeridad.

45. AHN, Estado, leg. 2863/1, doc. 33, Aranda a Angosto, 18 marzo 1792; y doc. 34, Angosto a Aranda, 19 marzo 1792: corrobora que entregó todos los originales a Floridablanca.

46. AHN, Estado, leg. 2863/1, doc. 25, citado. Y citas siguientes.

47. AHN, Estado, leg. 2863/1, doc. 36, Angosto a Aranda, 26 marzo 1792. 
para instruirse en el idioma inglés y perfeccionarse en el real servicio ${ }^{48}$. Esa petición o se perdió o no obtuvo respuesta. El 23 de mayo los mismos hermanos remitieron un memorial de su madre, quien ahora solicitaba bien una pensión en atención a los méritos del difunto padre bien una licencia para reingresar en el Regimiento de Hibernia ${ }^{49}$. Tampoco llegaron a la Secretaría de Estado ni el memorial ni la carta que lo acompańaba ${ }^{50}$. Por fin, tras una última petición les fue concedida la licencia, reingresando en el ejército como segundos tenientes ${ }^{51}$.

Los otros compañeros de aula denunciados por Wadingo figuraban en una lista de «Seminaristas que deben ser enviados à sus casas por ser muy perjudicial su permanencia a los demas»: Pardo, en un grupo de siete, "por incorregibles en sus vicios y aun alguno por malos principios prescindiendo de estar ya en edad de que se pueda mexorar su educación»; y Álvaro Navia, en otro de cuatro, "por su mucha edad y no estar en disposición de hacer progreso alguno en el Seminario» ${ }^{52}$.

Aranda durante su breve mandato no modificó las disposiciones relativas a la sala francesa, quedando la enseñanza del Francés a cargo del mencionado Dionisio Pelleport. La institución vivía tiempos de decadencia económica y, de ahí, educativa, y el siguiente secretario de Estado Manuel Godoy trató de paliarlas con las dos visitas que ordenó en 1793 y 1794.

Las declaraciones que durante la primera recabó Antonio de la Cuesta y Torre, arcediano de la catedral de Ávila que ejerció de secretario y visitador, revelan que aún estaban presentes en la mente de los entrevistados los incidentes de 1791-1792. Según se ha indicado, los directores José Pérez y Juan Bautista de Alzamora -y también Wadingo- denunciaron el proteccionismo que Angosto prodigaba al abate Lapeyre; y el capellán mayor Scuditti mencionó quejas «sobre el modo de pensar de algunos» que él ya había formulado al director «y despues reserbadamente à la Superioridad ${ }^{53}$. El sacristán mayor José Antonio Pérez Requejo precisaba: «Que el estrago gravisimo que habia traido a las costumbres de los seminaristas la Sala quinta por las ideas de su Director, se remedió en la

48. AHN, Estado, leg. 2863/1, doc. 38, Teresa viuda de Terry al secretario de Estado, sin fecha.

49. AHN, Estado, leg. 2863/1, doc. 37, José y Juan Terry al secretario de Estado, 23 mayo 1792. AHN, Universidades, leg. 689, exp. 4, doc. 5, memorial de la viuda Terry, sin fecha; al margen, petición de que se remita esa noche a Aranda todo lo relativo a José Terry.

50. AHN, Estado, leg. 2863/1, doc. 39, José y Juan Terry al secretario de Estado, sin fecha; Aranda anota al margen, el 8 de junio, dichos extravíos.

51. AHN, Universidades, leg. 689, exp. 1, conde de Campoalange a Aranda, 28 junio 1792; avisa de la resolución real sobre los Terry. Ambos solicitaron una ayuda para equiparse (AHN, Universidades, leg. 689, exp. 4, doc. 5, José y Juan Terry, 4 julio 1792).

52. AHN, Universidades, leg. 690/1, exp. 1, «Nota reservada». Navia está entre los «asistentes» del aula de lengua francesa de Pelleport, bastante numerosa, y como único calificado - «Bueno»en la de Derecho Natural y de Gentes de Andrés de Dios Cobo (AHN, Universidades, leg. 690/3, exp. 7; «Relacion de los Caballeros Seminaristas...», 30 septiembre y 30 noviembre 1793).

53. AHN, Universidades, leg. 690/2, exp. 5, f. 3v-4r, 3 febrero 1792. 
mayor parte» ${ }^{54}$. Aunque Manuel de Trigo, el director más neutral cuando los hechos, achacaba el cese de los desórdenes a la salida de algunos seminaristas ${ }^{55}$. Por otra parte, varios declarantes insistían en la incapacidad de Angosto como director, su falta de talento y la arbitrariedad de sus decisiones ante la inexistencia de normas fijas, su laxitud con los seminaristas y su absentismo, de donde derivaban las malas costumbres de antiguos alumnos, «algunos corrompidos y libertinos», según José Sánchez Ortiz, director de la Sala 6a . En cambio, Lorenzo Martínez, de la Sala 3a aún notaba «algunas expresiones en materias relativas a la Religion que en boca de jovenes eran peligrosas, necesitandose mayor discernimiento para no equivocar con grave perjuicio suio cosas de esta naturaleza ${ }^{56}$. Significativamente, algunos profesores -entre ellos el ultramontano Wadingo- insisten en la escasa capacitación intelectual e instrucción de los directores eclesiásticos.

El nuevo inquisidor general Manuel Abad y Lasierra rubricó los informes de cada visita. Como conclusión de la primera de 1793, determinó la necesidad de unas nuevas Constituciones para mejorar la educación y gobierno del Real Seminario y un Plan de reforma. Tras la segunda, Godoy decretó su redacción por una Real Orden del 14 de marzo de 1794, así como el retiro de Angosto, quedando Scuditti como director interino ${ }^{57}$. Publicadas en 1799 , mantenían el Francés, materia fundamental y obligatoria, complementaria de la Poética y Retórica castellana y latina, y aconsejaban para la asignatura la versión de libros «clásicos» de Bossuet, La Porte y Batteux (Constituciones 1799: 40).

Sin duda, la Revolución había sembrado muchos miedos, según muestra el Plan de Educación de González Cañaveras, antes mencionado, que pasó de ponderar la enseñanza de las lenguas como su primer objetivo en la edición de 1767 a articularlo en torno a «aprender la Religión, formar las costumbres, y cultivar el entendimiento» en la de 1794 (Fernández Fraile 100-101). En cuanto a los profesores del Real Seminario, continuaba impartiendo francés el catedrático Pelleport, al que se sumó en 1800 el maestro Josef Savatier. Mientras, algunos de los expedientados por Floridablanca continuaron sus carreras de modo particular: el chismoso Laures, dedicado enseguida a la docencia privada y autor de textos didácticos ${ }^{58}$, como también el desterrado

54. AHN, Universidades, leg. 690/2, exp. 5, f. 11 r.

55. AHN, Universidades, leg. 690/2, exp. 5, f. 8r. Pedro Luján, el director que menos peligros advirtió en las palabras Lapeyre, había fallecido (AHN, Universidades, leg. 690/1, Angosto a Alcudia, 15 enero 1793).

56. AHN, Universidades, leg. 690/2, exp. 5, José Sánchez Ortiz (f. 9r) y Lorenzo Martínez (f. 6v).

57. AHN, Universidades, leg. 690/2, exp. 5 (s. p.), Alcudia al Inquisidor General, 14 marzo 1794. El primer informe es del 27 de abril de 1793 (ibid., f. 24rv).

58. Juan Tomás Laurés de Mayrán, Tratado de conjugación francesa, en que se explican todas sus especies, modos, tiempos, personas y terminaciones, Madrid, Imprenta de Joseph Fraganillo, 1797; Compendio nuevo de gramática francesa, Valladolid, Joseph Herreros, 1799; Nueva gramática francesa..., Madrid, librería de Escribano, 1800. 
Laborda $^{59}$, que ambos firmaban como excatedráticos de la institución. Y el abate Lapeyre solicitó se le mantuviera la pensión que le fue asignada tras ser suprimida la revuelta Sala $5^{a}$ que dirigió ${ }^{60}$.

A finales de 1792 Andrés de Dios Cobo se había convertido en el nuevo catedrático de Derecho Natural y de Gentes del Real Seminario ${ }^{61}$. Su predecesor Condado, que tenía buenos padrinos, pasó a ocupar ese año la cátedra homóloga en los Reales Estudios de San Isidro, fallecido su titular y gracias a un informe de Abad y Lasierra -su director desde agosto- a favor de la continuidad de la asignatura, tan incómoda ${ }^{62}$. Ya en 1794 una Real Orden suprimió todas las cátedras y enseñanzas del joven Derecho Natural y de Gentes y Derecho Público ${ }^{63}$; sus directrices se reflejaron en las nuevas Constituciones del Real Seminario de Nobles: «habrá un Catedrático de Lógica y Metafísica, que la enseñe un año: otro de Física general y particular experimental que la enseñará en igual tiempo; y otro de Filosofía moral en que se unan la Moral, la Religion y la Política, cuya enseñanza se completará en el tercer año» (Constituciones 1799: 42). Wadingo continuó brevemente en su cátedra de Filosofía Moral ${ }^{64}$, asignatura añadida en las Constituciones de 1755 que interfirió con frecuencia en las enseñanzas jurídicas y que ahora ligaba la política a la religión católica ${ }^{65}$.

Algo antes, en 1787, en la Universidad de Salamanca un grupo de profesores ilustrados habían solicitado la creación de un Colegio de Filosofía, con el que pretendían encumbrar esa facultad -en la parte baja junto con las Artes-, segregarla de la teología y ampliar sus contenidos; su aprobación en 1792 originó la reacción del sector ultramontano ante el Consejo de Castilla, con el subsiguiente encarcelamiento de Ramón de Salas por la Inquisición

59. Reglas para la pronunciación y gramaticales de lengua francesa, coordinadas por D. Esteban de Bordes, catedrático del Real Seminario de Nobles, Madrid, En la Imprenta de Sancha, 1801, 62 p.; era ampliación del mismo título de 1784 .

60. AHN, Universidades, leg. 689, exp. 7, Lapeyre al secretario de Estado, 21 mayo 1792.

61. AHN, Universidades, leg. 689, exp. 2, Angosto a Alcudia, 27 diciembre 1792. Andrés de Dios Cobo aún se declara catedrático de Lógica y Metafísica cuando la primera visita del inquisidor al Real Seminario (AHN, Universidades, leg. 690/2, exp. 5, f. 15v, 10 febrero 1793); con la nueva cátedra, en la segunda (s. p., 28 febrero 1794).

62. Condado obtuvo su cátedra en el Real Seminario de Nobles en 1783, recomendado a Floridablanca por Felipe Bertrán, arzobispo de Salamanca e Inquisidor general (Viñao Frago 1195), y en 1792 la de los Reales Estudios sin superar la oposición preceptiva; el informe requerido entonces al director Abad y Lasierra, tras reconocer los peligros del Derecho Natural y sus cultivadores extranjeros, sugería que la vacante fuese ocupada por un conocedor del «espíritu de los Autores libres», capaz de "segregar la doctrina sana y útil a sus Discipulos» (ibid. 11981199). En 1800-1801 fue encargado de negocios de España ante la República Cisalpina.

63. Sobre la Real Orden, del 31 de julio de 1794, ver Rus Rufino (142-143). Para Jara Andreu su intención era prevenir «la difusión de un iusnaturalismo racionalista, secularizado y, potencialmente, revolucionario» (89), mientras Viñao Frago (1192-1193) la cree correctiva de unos conocimientos ya difundidos.

64. Su cátedra quedó vacante enseguida, siendo solicitada por Josef Antonio de Manegat (AHN, Universidades, leg. 690/1, exp. 2, 5 septiembre 1794).

65. La Filosofía Moral tenía el papel de sujetar las luces de la Razón a la religión católica ya en el decreto de fundación de los Reales Estudios de San Isidro, como destaca Jara Andreu (51). 
y su expulsión del claustro universitario, aunque en 1799 el pleito acabó a su favor (Robledo 29-34). Otro episodio de colisión de las nuevas ideas con las estructuras ideológicas tradicionales en la misma universidad donde se formó Condado. En cualquier caso, continuaron impartiéndose en España enseñanzas con contenido filosófico-jurídico, y algunas propuestas posteriores manifestaban la estima por el Derecho Natural moderno, cuyos presupuestos ideológicos pudieron desempeñar un papel importante en la evolución de la Ilustración española al liberalismo ${ }^{66}$.

La monarquía española volvió a su tradicional alianza francesa con la Paz de Basilea de 1795, ahora con el régimen republicano. Entretanto, el Real Seminario de Nobles continuó deteriorándose por razones económicas o de gestión y luego por las circunstancias bélicas (Andújar Castillo 207-209; Aguilar Piñal 345-347). Representó, no obstante, un proyecto ilustrado coherente para formar a las élites españolas, en que resultaba indispensable el francés, la lengua del trato social entre los europeos cultivados. Y reveló su apertura a disciplinas emergentes, fruto de las novedades filosóficas, como el Derecho Natural y de Gentes, que, basado en la Razón, podía cuestionar las ideas recibidas. Orientado a formar a los futuros dirigentes, el Gobierno procuró tanto su buen funcionamiento como el control de contenidos impartidos y de profesores y alumnos. Floridablanca lo ejerció con rigor durante su mandato, alertado por denuncias externas interesadas o con la ayuda de informantes ultramontanos internos, incapaz de rehuir la alarma del "francesismo» en materia de libertad religiosa y política. Su sucesor Aranda revisó con más objetividad los expedientes abiertos y minimizó los peligros advertidos, mientras Godoy, estabilizada la relación con Francia, se preocupó por los problemas coyunturales.

\section{Bibliografía}

Aguilar Piñal Francisco, 1980, «Los reales Seminarios de Nobles en la política ilustrada española», Cuadernos Hispanoamericanos, 356. 329-349.

Albiac María-Dolores, 1998, El Conde de Aranda. Los laberintos del poder, Zaragoza, CAI, $175 \mathrm{p}$.

Álvarez de Morales Antonio, 2007, «El salmantino Condado y la difusión del Derecho Natural y de Gentes», en Luis E. Rodríguez-San Pedro Bezares y Juan Luis Polo Rodríguez (eds.), XIV Coloquios Alfonso IX. Universidades hispánicas. Modelos territoriales en la Edad Moderna (II), Salamanca, Universidad de Salamanca, vol. I, 271-281.

Andújar Castillo Francisco, 2004, «El Seminario de Nobles de Madrid en el siglo XVIII. Un estudio social», Cuadernos de Historia Moderna. Anejos, III. 207-209.

66. Ver Jara Andreu (71-85, 89-90), que revisa las propuestas jurídicas de Jovellanos, y Viñao Frago (1205), que plantea el influjo de la generación de Condado y del Derecho Natural en dicha transición ideológica a fines del siglo XVIII. 
Cervera Ferri Pablo, 12-14 diciembre 2007, «La enseñanza de la economía en el Real Seminario de Nobles de Madrid (1770-1807)», V Encuentro de la Asociación Ibérica de Historia del Pensamiento Económico, Madrid. Disponible en http://www.estrellatrincado.com/CERVERA-AIHPE5.doc. consultado el 3 de marzo de 2014.

Constituciones de el Real Seminario de Nobles, fundado en el Colegio Imperial de la Compañia de Jesús de Madrid, por el Señor Don Phelipe Quinto...en Decreto de 21 de Septiembre de 1725, 1730, Madrid, Gabriel del Barrio, 44 p.

Constituciones del Real Seminario de Nobles de Madrid, 1755, s. 1., 240 p.

Constituciones del Real Seminario de Nobles de Madrid, 1799, Madrid, Imprenta Real, por D. Pedro Julián Pereyra, 114 p.

Elorza Antonio, 1989, «El temido Árbol de la Libertad», en Jean-René Aymes (ed.), España y la Revolución francesa, Barcelona, Crítica, 69-117.

Exercicios literarios de rudimentos de lengua latina y francesa, de poética y retórica, de lógica, metafisica y éthica, de derecho natural, de gentes y politica, de matemáticas, de fisica experimental, de geografia, uso del globo terrestre y historia de España y sagrada, que se han de tener en el Real Seminario de Nobles de esta Corte los dias 13 [...] y 21 de diciembre de 1788..., Madrid, En la Imprenta de la Viuda de Ibarra, s. p. continua.

Fernández Fraile María Eugenia, 2009, "Juan Antonio González Cańaveras y la enseñanza de lenguas en el siglo XVIII", Documents pour l'histoire du français langue étrangère ou seconde, 42. 87-108.

Fernández Fraile María Eugenia, Suso López Javier, 1999, La enseñanza del francés en España (1767-1936). Estudio histórico: objetivos, contenidos, procedimientos, Granada, Método Ediciones, 422 p.

García Bascuñana, Juan F. (coord.), 2017, Diccionario de historia de la enseñanza del francés en España (siglos XVI-XX) (DHFE), Universitat Rovira i Virgili. Disponible en http://www.grelinap.recerca.urv.cat/projectes/diccionario-historia-ensenanzafrances-espana/es_index/, consultado el 11 de mayo de 2018.

Herr Richard, 1990, España y la revolución del siglo XVIII, Madrid, Aguilar, 421 p.

Jara Andreu Antonio, 1977, Derecho Natural y conflictos ideológicos en la Universidad española (1750-1850), Madrid, IEA, 305 p.

Lépinette Brigitte, 2000, L'enseignement du français en Espagne au XVIII' siècle dans ses grammaires: contexte historique, concepts linguistiques et pédagogie, Münster, Nodus, $381 \mathrm{p}$.

Peset José Luis, 1981, "Ciencia, nobleza y ejército en el Real Seminario de Nobles de Madrid (1770-1788)», en Mayans y la Ilustración. Simposio Internacional en el Bicentenario de la muerte de Gregorio Mayans, Valencia, Ayuntamiento de Oliva, 2. 519-535.

Peset Mariano, Peset José Luis, 1975, Gregorio Mayans y la reforma universitaria, Valencia, Publicaciones del Ayuntamiento de Oliva, 363 p.

Plan de Estudios y habilidades que por ahora se tienen y enseñan en el Real Seminario de Nobles..., 1785, Madrid, Joachin Ibarra, 21 p.

Robledo Ricardo, 2012, "Juan Justo García», en José María Lama (ed.), Los primeros liberales españoles. La aportación de Extremadura. 1810-1854 [Biografias], Badajoz, Diputación de Badajoz, «Colección Historia», 27-48. 
Salvá Vicente, 1846, Nuevo diccionario de la lengua castellana..., París, Librería de don Vicente Salvá, 1140 p.

Rus Rufino Salvador, 1993, Historia de la Cátedra de Derecho Natural y de Gentes de los Reales Estudios de San Isidro (1770-1794). Sobre el problema del origen de la disciplina Derecho Natural en España, León, Servicio de Publicaciones de la Universidad de León, 202 p.

Vińao Frago Antonio, 1997, «Manuel Joaquín de Condado y la cátedra de Derecho Natural y de Gentes de los Reales Estudios de San Isidro (1770-1794)», en Estudios de derecho constitucional y de ciencia politica: homenaje al profesor Rodrigo FernándezCarvajal, Universidad de Murcia, vol. II, 1187-1206. 
